\title{
A Stable Live Bacterial Vaccine
}

Nitesh K Kunda ${ }^{1}$, Denis Wafula ${ }^{1,2}$, Meilinn Tram ${ }^{1}$, Terry $\mathrm{H} \mathrm{Wu}^{3,4}$, Pavan Muttil ${ }^{1}$

${ }^{1}$ Department of Pharmaceutical Sciences, College of Pharmacy, University of New Mexico, Albuquerque, New Mexico, USA; ${ }^{2}$ Department of Cell Biology and Molecular Genetics, University of Maryland, Maryland, USA; ${ }^{3}$ Department of Internal Medicine, University of New Mexico, Albuquerque, New Mexico, USA; ${ }^{4}$ Center for Infectious Disease and Immunity, University of New Mexico, Albuquerque, New Mexico, USA

Corresponding Author: Dr. Pavan Muttil, Department of Pharmaceutical Sciences, College of Pharmacy, University of New Mexico, Albuquerque, 87131 NM, USA; Email: pmuttil@salud.unm.edu;

The authors declare no conflict of interest.

Keywords: cold chain; dry powder; live bacterial vaccine; spray-drying; thermostable; viability

Abbreviations: Ft, Francisella tularensis; Lm, Recombinant attenuated Listeria monocytogenes expressing the $\mathrm{Ft}$ immune protective antigen pathogenicity island protein $\mathrm{IglC}$; $\mathrm{RH}$, Relative Humidity; MTDLI, Mannitol, Trehalose, Dextran, L-leucine, Myo-inositol 


\section{Abstract}

Formulating vaccines into a dry form enhances its thermal stability. This is critical to prevent administering damaged and ineffective vaccines, and to reduce its final cost. A number of vaccines in the market as well as those being evaluated in the clinical setting are in a dry solid state; yet none of these vaccines have achieved long-term stability at high temperatures. We used spraydrying to formulate a recombinant live attenuated Listeria monocytogenes (Lm; expressing Francisella tularensis immune protective antigen pathogenicity island protein IglC) bacterial vaccine into a thermostable dry powder using various sugars and an amino acid. Lm powder vaccine showed minimal loss in viability when stored for more than a year at ambient room temperature $\left(\sim 23{ }^{\circ} \mathrm{C}\right)$ or for 180 days at $40{ }^{\circ} \mathrm{C}$. High temperature viability was achieved by maintaining an inert atmosphere in the storage container and removing oxygen free radicals that damage bacterial membranes. Further, in vitro antigenicity was confirmed by infecting a dendritic cell line with cultures derived from spray dried Lm and detection of an intracellularly expressed protective antigen. A combination of stabilizing excipients, a cost effective one-step drying process, and appropriate storage conditions could provide a viable option for producing, storing and transporting heat-sensitive vaccines, especially in regions of the world that require them the most. 


\section{Introduction}

Vaccines have saved more lives in the history of mankind than any other medical intervention. More than 3 million deaths are currently prevented each year by the use of vaccines, also saving billions of dollars in medical treatments [1]. Vaccines have contributed towards the eradication of smallpox [1]. Another success is the MenAfriVac vaccine that has been effective in reducing the number of meningitis A cases in Sub-Saharan Africa [2]. A common theme for the success of smallpox vaccine almost half a century ago and recently the MenAfriVac vaccine was their ability to withstand high temperature conditions during storage and transportation $[2,3]$. However, majority of the vaccines that are currently available in the market require an uninterrupted coldchain throughout the shelf-life of the product. This limits the reach of vaccines to remote regions in low-and-middle income countries that do not have adequate cold-chain infrastructure [4]. As a result, significant mortality is reported around the world due to poor vaccine coverage [5].

Conventional vaccines consisting of aqueous formulations are at greater risk for physical and chemical degradation compared to dry formulations [6,7]. Antigens in aqueous vaccine formulations often encounter physical instability such as denaturation, aggregation, and precipitation. These reactions lead to an altered antigen structure resulting in vaccine becoming ineffective [8]. Alternatively, antigens in the dry state can overcome instability by the addition of glass-forming excipients such as trehalose. Moreover, dry vaccines are able to withstand higher temperatures and minimize the need for cold-chain logistics during vaccine storage, transport, and administration [9].

Spray-drying is a technique that has gained significant attention in formulating dry powder vaccines mainly for its ease of use and simple scale-up for mass production [10,11]. It is a singlestep process that converts liquid feed into dry powders. The liquid feed is atomized to spray 
droplets that upon contact with an inert gas causes rapid evaporation resulting in dry powders. With the help of a cyclone, the powders are then separated from the gas and collected into a vessel [12]. Spray-drying of live bacteria with sugars and amino acids provide stability to the bacterial cell wall from environmental stresses $[13,14]$. In addition, dehydration is necessary for long-term preservation of live bacteria [15].

Spray-dried powders can be engineered to desired particle size appropriate for the pulmonary route of delivery [16]. Most of the current vaccines are administered with needles and syringes [17]. Immunization using needles is painful and requires trained medical personnel for administration presenting an occupational risk of needle-stick injury [10]. However, pulmonary delivery of vaccines has the advantage of being needle-free and elicit mucosal immune responses at the site of entry for many pathogens [18,19].

Our goal was to develop a dry powder formulation of a live bacterial vaccine that can easily be manufactured, deployed to remote regions without a cold-chain and administered to at-risk military personnel as a needle-free strategy. As a proof-of-concept, a recombinant live attenuated Listeria monocytogenes $(\mathrm{Lm})$ based vaccine against Francisella tularensis $(\mathrm{Ft})$ was formulated as a dry powder.

Ft is a gram-negative facultative intracellular pathogen, that causes the disease 'tularemia' [20]. Pneumonic tularemia is the most serious and potentially fatal form of the disease is acquired by inhalation of the bacteria; infections are also acquired from exposure with infected animals or arthropod bites [21]. Ft was used as a biological weapon during World War II and no licensed vaccine is currently available against this disease [22,23]. The recent focus has been to use the pathogenic factor of $\mathrm{Ft}$, IglC (intracellular growth locus subunit $\mathrm{C}$ ), in developing an effective 
vaccine against Ft. It is an essential virulence factor and is effective as an immune protective antigen in a vaccine against tularemia [24].

$\mathrm{Lm}$ are Gram-positive facultative anaerobic bacteria. The Lm infection model has been used to understand the development of host cellular immune responses through its targeting of both major histocompatibility class I and II pathways, which are critical pathways to generate protective immunity [25]. Live attenuated Lm expressing tumor antigens is currently being developed as a therapeutic vaccine to treat cancer [26-30]. Here, we use a live attenuated Lm strain engineered to express Ft pathogenicity island protein, IglC, which has been shown to be effective against lethal Ft challenge [24].

In these studies, we demonstrate thermostability of dry powder live Lm vaccine at temperatures up to $40{ }^{\circ} \mathrm{C}$. We demonstrate high temperature stabilization for Lm by using suitable excipients, storage conditions, and an easily scalable manufacturing process. The findings presented here could be applied to different heat-sensitive vaccines currently in the market. This could be a major step towards providing effective vaccines in countries that lack cold-chain infrastructure. 


\section{Materials and Methods}

Materials. Dextran (Dex) and D-(+)-Trehalose dihydrate (Tre) were purchased from MP Biomedicals, Solon, OH. D-(-) Mannitol (Man) and myo-Inositol (Ino) were purchased from EMD Millipore, Billerca, MA. L-Leucine (>98\%) (Leu), and sodium hydroxide $(\mathrm{NaOH}, 10 \mathrm{~N})$ were purchased from Sigma-Aldrich, Milwaukee, WI. Yeast extract was purchased from BD Biosciences, NJ. Potassium phosphate $\left(\mathrm{KH}_{2} \mathrm{PO}_{4}\right)$ was purchased from EMD Millipore, USA. The Brain Heart Infusion (BHI) agar plates were purchased from Hardy Diagnostics, Santa Maria, CA. Dulbecco's Phosphate Buffered Saline (DPBS) w/o magnesium and calcium was purchased from Life technologies, Grand Island, NY.

Culturing Lm. Recombinant attenuated L. monocytogenes ( $\triangle a c t A \triangle i n l B \Delta u v r A B \operatorname{prfA} *(\mathrm{G} 155 \mathrm{~s})$ strain) expressing the Ft immune protective antigen, pathogenicity island protein $\mathrm{IglC}$, was obtained from Aduro Biotech, Inc, CA, USA. The Lm was grown by ice scraping from a frozen glycerol stock stored at $-80{ }^{\circ} \mathrm{C}$ in $\mathrm{YNG}$ media (yeast extract $25 \mathrm{~g} / \mathrm{L}, \mathrm{KH}_{2} \mathrm{PO}_{4} 9 \mathrm{~g} / \mathrm{L} \mathrm{pH}$ adjusted to 7.2 using $10 \mathrm{~N} \mathrm{NaOH}$ ). The culture was grown at $37^{\circ} \mathrm{C}$ for $16-26 \mathrm{~h}$ with shaking at $220 \mathrm{rpm}$.

\section{Spray-drying of Lm}

Preparation of Lm Suspension. To prepare Lm for spray-drying, $200 \mathrm{~mL}$ of the culture (approx. 2$5 \times 10^{9} \mathrm{cfu} / \mathrm{mL}$ ) was centrifuged $\left(4000 \mathrm{~g}\right.$ and $4{ }^{\circ} \mathrm{C}$ for $\left.30 \mathrm{~min}\right)$ and the resultant pellet was washed by suspending in $50 \mathrm{~mL}$ of $2.05 \%(\mathrm{w} / \mathrm{v})$ sterile spray-drying solution. The spray-drying solution comprised of 85.4\% Mannitol (M), 1.71\% Trehalose (T), 0.85\% Dextran (D), 7.85\% L-Leucine (L) and 4.27\% Inositol (I); MTDLI. The Lm suspension was centrifuged again and the resulting pellet was re-suspended in $70 \mathrm{~mL}$ of the MTDLI solution. The Lm suspension in MTDLI was plated in triplicates prior to spray-drying to obtain the CFUs (colony forming units). 
Spray-drying Conditions. A Büchi Mini Spray Dryer B-290 fitted with a standard two-fluid nozzle (0.7 mm diameter) (Büchi Corporation, Flawil, Switzerland) was used for spray-drying Lm. Spraydrying was conducted according to protocols reviewed and approved by the Institutional Biosafety Committee (IBC) at the University of New Mexico. The parameters for spray-drying were: inlet temperature $130{ }^{\circ} \mathrm{C}$, outlet temperature of $47 \pm 2{ }^{\circ} \mathrm{C}$, nitrogen flow rate of $742 \mathrm{~L} / \mathrm{h}$ and aspirator rate of $100 \%$. The feed rate was set at $10 \%$ corresponding to $6 \mathrm{~mL} / \mathrm{min}$. A $0.2 \mu \mathrm{m}$ EMFLON Filter (Pall Life Sciences, USA) was attached in-line to the exhaust of the spray-dryer immediately after the PTFE membrane filter to prevent release of $\mathrm{Lm}$ to the atmosphere. In addition, the spray-dryer was housed in a BioPROtect III Jr® Bio Safety Cabinet (BSC, Baker Co., Sanford, ME; BSL-2 contained) to provide protection to the dry powder vaccine from contamination and the operator from exposure to Lm. All subsequent handling of the powders were performed in a BSC according to the IBC approved protocol. The spray-dried powders were immediately stored in glass vials sealed with parafilm and stored at different conditions until further use.

\section{Dry Powder Characterization}

Spray-drying Yield. The dry powder yield was determined as the difference in the weight of the sample vial before and after product collection. The weight difference was compared to the initial total dry mass and the yield in $\%(w / w)$ was calculated $(n=3)$. All values are reported as Mean \pm SD.

Bacterial Loading. The bacterial loading was determined by suspending $1 \mathrm{mg}$ of the spray-dried Lm dry powder in $1 \mathrm{~mL}$ of Dulbecco's PBS, serially diluted and plated on BHI agar plates. Viable colonies were counted after incubation at $37^{\circ} \mathrm{C}$ for $24 \mathrm{~h}$.

Particle Sizing. The particle size distributions of the blank and Lm dry powders were analyzed by a Mastersizer 3000 (Malvern Instruments Ltd, USA) using the dry powder dispersion system (Aero 
$\mathrm{S}$, Malvern Instruments Ltd). About $5 \mathrm{mg}$ of the powder was placed in the sample cup of the Aero $\mathrm{S}$ and particle size measurements were carried out at a feed rate of 60 , sheer pressure of 2 bar and a sample run time of $25 \mathrm{~s}$. The average particle size distribution was measured from three replicates of each sample.

Morphology. The Lm bacteria were visualized before and after spray-drying using transmission electron microscopy (TEM, JEOL 200CX TEM operated at $200 \mathrm{kV}$ ). Briefly, the Lm spray-dried powders were dispersed and fixed in 10\% v/v paraformaldehyde (Sigma Aldrich) prior to imaging. The suspension was then negatively stained with $0.25 \%$ phosphotungstic acid (PTA) and images captured at different magnifications.

The surface morphology of the spray-dried Lm was characterized using a scanning electron microscopy (SEM; Hitachi S-5200 field-emission scanning electron microscope). The powders containing Lm were mounted on a double-sided carbon tape on an aluminum boat for examination. The particles were then visualized with a resolution of $2 \mathrm{~nm}$ at low voltages $(1 \mathrm{kV})$ and currents to prevent collapse of the powders.

IglC expression in Dry Powders. The ability of Lm dry powders to express IglC antigen after spray-drying was determined by Western Blot. Briefly, powders were dissolved in sodium dodecyl sulfate (SDS) sample buffer (15 mg/mL; NuPAGE LDS Sample Buffer, ThermoFisher), vortexed, incubated at $95{ }^{\circ} \mathrm{C}$ for $5 \mathrm{~min}$ and loaded directly onto a gel (NuPAGE Novex 4-12\% Bis-Tris protein gel, ThermoFisher). Proteins were transferred to nitrocellulose membranes for Western blot analysis using a polyclonal antibody raised against the N-terminus of the Lm ActA protein, which was fused to the $\mathrm{N}$-terminus of $\mathrm{Ft} \mathrm{IglC} \mathrm{antigen} \mathrm{to} \mathrm{enhance} \mathrm{its} \mathrm{expression} \mathrm{and} \mathrm{secretion.} \mathrm{A}$ secondary antibody (IRDye 680RD donkey anti-rabbit, Li-Cor) and Li-cor Odyssey were used to image the blots. 
Intracellular IglC expression in DC2.4 cells. For analysis of intracellular antigen expression, powders were dissolved in sterile water $(10 \mathrm{mg} / \mathrm{mL})$, vortexed and incubated for $30 \mathrm{~min}$ at room temperature. An aliquot of the resulting powder suspensions $(50 \mu \mathrm{L})$ was used to inoculate overnight $30{ }^{\circ} \mathrm{C}$ cultures (Brain Heart Infusion broth, $1 \mathrm{~mL}$ ). The following morning, cultures were diluted in tissue culture media (Roswell Park Memorial Institute 1640 medium supplemented with $10 \%$ fetal bovine serum, $\beta$-mercaptoethanol, L-glutamine, HEPES buffer, sodium pyruvate and nonessential amino acids) and used to infect a murine DC2.4 dendritic cell line at a multiplicity of infection of 10. Infections were allowed to proceed for $1 \mathrm{~h}$ at $37^{\circ} \mathrm{C}$, media was aspirated, cells were washed once with phosphate-buffered saline (PBS) and fresh media containing gentamycin $(50 \mu \mathrm{g} / \mathrm{mL})$ was added. DC2.4 cells were harvested after an 8 hour incubation by removing the media, washing once with PBS and resuspending in SDS sample buffer. Samples were further prepared by incubating at $95^{\circ} \mathrm{C}$ for $5 \mathrm{~min}$, vortexing and centrifugation $(18,000 \mathrm{~g}$ for $5 \mathrm{~min})$ prior to loading on a gel. Western blotting was performed as for dry powder analysis (above).

Moisture Content. Thermogravimetric analysis (TGA) was used to determine the moisture content in the spray-dried Lm samples. Measurements were carried out using a thermal analyzer TA Instrument SDT Q600 which provides an accurate measurement of weight change. Dry powder Lm samples $(5-10 \mathrm{mg})$ were loaded into a sample pan with a sensitive microbalance and heated from 20 to $150{ }^{\circ} \mathrm{C}\left(5 \mathrm{~K} \mathrm{~min}^{-1} \mathrm{ramp}\right)$ under $\mathrm{N}_{2}$ gas. The water content was analyzed for data collected between 20 to $150^{\circ} \mathrm{C}$.

Long-term Storage Stability. The Lm powders were weighed into scintillation glass vials or amber colored serum bottles (referred to as storage bottles) immediately after spray-drying and stored at $4{ }^{\circ} \mathrm{C}$, RT $\left(22 \pm 2{ }^{\circ} \mathrm{C}\right)$, or $37{ }^{\circ} \mathrm{C}$. Moreover, the Lm powders were stored along with desiccants (Minipax ${ }^{\circledR}$ absorbent packets, Sigma-Aldrich), inert gas $\left(\mathrm{N}_{2}\right.$ gas), and oxygen scavenger 
(PharmaKeep® canisters CD-1G or packet KD-20, Mitsubishi Gas Chemical Company, Inc.) either alone or as a combination to evaluate the vaccine's stability at higher temperatures and humidity conditions. The RH and temperature inside the storage bottles were captured using a wireless Miniature temp/RH logger (Omega Engineering Inc., USA). In addition, the Lm powders that maintained stability at appropriate storage conditions were further evaluated at $40{ }^{\circ} \mathrm{C}$ under different RH conditions (15 and 75\% RH) based on the ICH guidelines for vaccine storage [31,32]. The Lm powders were withdrawn at regular intervals and cfu's counted as described previously. As a control, Lm in liquid suspension (PBS) was stored unprotected at $4{ }^{\circ} \mathrm{C}$, RT, and $25^{\circ} \mathrm{C}$; aliquots were plated at 3 and 6 week and viable colonies counted as before.

Nitrogen Purging. Nitrogen gas was purged into the amber colored serum bottles as a strategy to maintain the viability of the Lm powders. We fabricated a nitrogen purging device as shown in Suppl. Fig. 1. For the $\mathrm{N}_{2}$ purging experiments, scintillation glass vials were replaced with a $10 \mathrm{~mL}$ Wheaton glass bottles (amber colored, Sigma). The storage bottles were filled with freshly prepared Lm powders and sealed with $20 \mathrm{~mm}$ butyl rubber septa (Supelco, 27232, Sigma). The rubber sealed bottles were then purged with $\mathrm{N}_{2}$ gas and crimped with tear-away aluminum seals (Supleco, 27016, Sigma) using a vial seal crimper. Briefly, two hypodermic needles (22 gauge) were inserted through the butyl rubber septum of the crimped bottle (S Fig. 1B). One needle was connected to the nitrogen cylinder via a tubing to flush the $\mathrm{N}_{2}$ gas into the storage bottle and the other needle served to evacuate the oxygen out of the bottle. In addition, cotton wool was placed in the bottle to prevent aerosolization of the powders during $\mathrm{N}_{2}$ gas purging (S Fig. 1C).

Membrane integrity study. We studied the membrane integrity of Lm dry powder upon exposure to environmental factors such as temperature, humidity, and oxygen. The bacterial membrane damage is indicated by the release of intracellular cytoplasmic material from the bacteria. The 
released biologic material such as DNA and RNA can be detected by measuring the absorbance at $260 \mathrm{~nm}$ since these nucleotides have a strong UV absorption at this wavelength [33]. Briefly, preweighed Lm dry powder was either packaged unprotected or protected and exposed to the environmental factors $\left(37^{\circ} \mathrm{C}, 100 \% \mathrm{RH}\right)$. After one week, the Lm dry powder was reconstituted in PBS $(5 \mathrm{mg} / \mathrm{mL})$ and filtered using a $0.22 \mu \mathrm{m}$ filter to remove whole/intact bacteria. The cell components that passed through the filter were then measured at $260 \mathrm{~nm}$. For positive control, the Lm dry powder suspension in PBS was probe sonicated for $5 \mathrm{~min}$ at high amplitude to ensure complete breakage of cells and release of intracellular components.

Endotoxin Quantification. The amount of endotoxin present in the Lm dry powders was quantified using a commercially available kit (Pierce ${ }^{\mathrm{TM}}$ Limulus Amebocyte Lysate (LAL) Chromogenic Endotoxin Quantification Kit, Life technologies, USA). Briefly, the Lm dry powders (1 mg/mL) were dissolved in endotoxin-free water and diluted to fall within range of the standard curve. Samples were measured on a microplate absorbance reader at $405 \mathrm{~nm}$.

\section{Results}

Spray-Drying

The attenuated Lm vaccine was grown in YNG media overnight at $37{ }^{\circ} \mathrm{C}$ and suspended in a solution containing stabilizing excipients (mannitol (M), trehalose (T), dextran (D), L-lecuine (L), and inositol (I); MTDLI) for spray-drying. Each of these excipients was selected to provide protection to the bacteria during drying and long-term storage (Table 1). Preliminary formulation design and optimization was performed by spray-drying the above excipients in different combinations and varying the total solid concentration, with powder yield and bacterial loading being the response parameters (data not shown). 
Table 1: Properties of Excipients used for Spray-drying Live attenuated Lm

\begin{tabular}{llc}
\hline Excipients & Properties & References \\
\hline Mannitol, M & Low hygroscopy & {$[34-36]$} \\
Trehalose, T & Lyoprotectant; High glass transition temperature & {$[36,37]$} \\
Dextran, D & $\begin{array}{l}\text { Decreases crystallization and increases glass } \\
\text { transition of dry powders }\end{array}$ & {$[35,38,39]$} \\
Leucine, L & $\begin{array}{l}\text { Low hygroscopy; Increases dispersibility of the dry } \\
\text { powder }\end{array}$ & {$[40-42]$} \\
Inositol, I & Enhances bacterial survival during spray drying & {$[37,43-45]$} \\
\hline
\end{tabular}

\section{Dry Powder Characterization}

Yield, Bacterial Loading, and Membrane Integrity. A spray-drying yield of $74.16 \pm 10.43 \% \mathrm{w} / \mathrm{w}$ was obtained for the Lm dry powders. The bacterial loading as determined by plating and counting colonies was $2 \times 10^{7}$ to $7 \times 10^{7} \mathrm{cfu} / \mathrm{mg}$ of the dry powder. Figure 1 shows the transmission electron images of Lm before and after spray-drying. The bacterial cell membrane integrity was preserved after spray-drying.

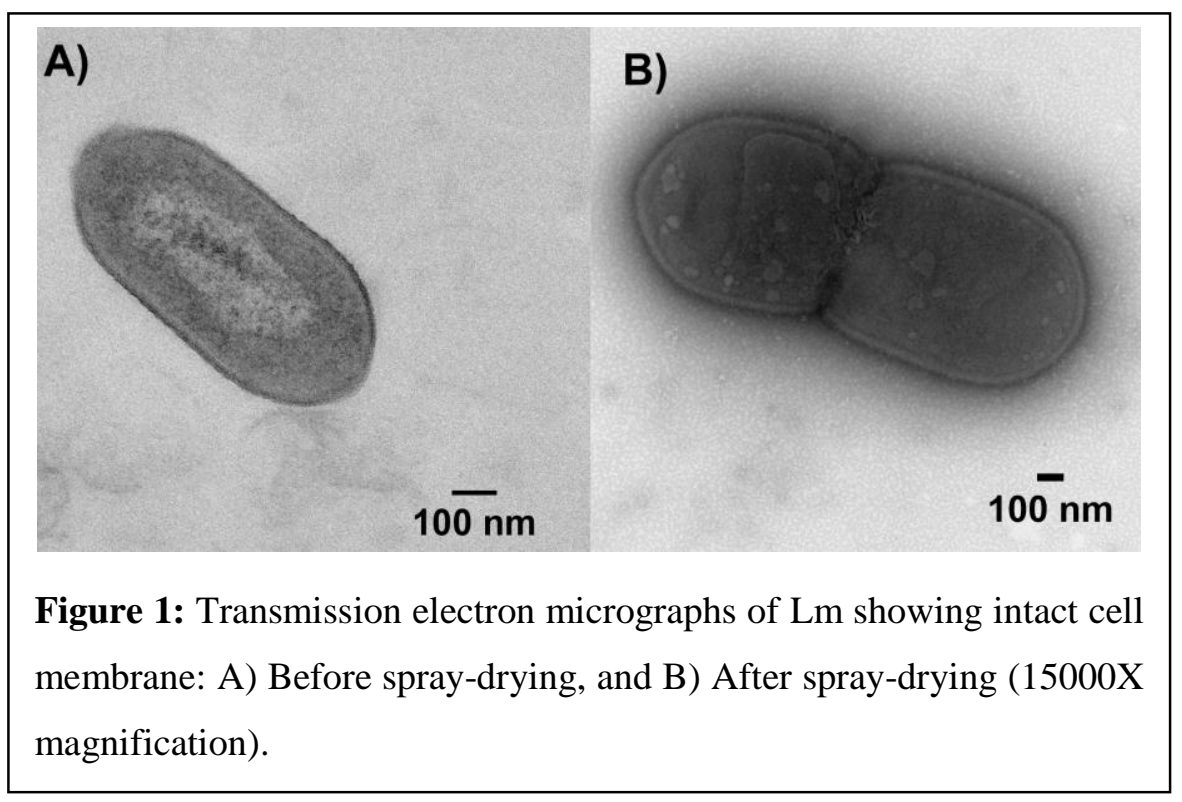


Particle Sizing. The empty and the Lm containing dry powders were sized using laser diffraction, and the results expressed as geometric diameter (dg). The dg value was $2.01 \pm 0.13 \mu \mathrm{m}$ for empty dry powders and $2.24 \pm 0.28 \mu \mathrm{m}$ for the Lm loaded dry powders, a minimal increase in size after encapsulation. The residual moisture content in the Lm dry powders was $0.71 \% \mathrm{w} / \mathrm{w}$ as determined using TGA.

The SEM pictures of the spray-dried powders were composed of smooth spherical particles. Complete encapsulation of the Lm was achieved after spray-drying although a few bacteria were observed outside of some particles (Fig. 2, arrow). This is in agreement with our calculations in section 'Number of Live bacteria per Microparticle', where we found that viable Lm were not present in all the dry powders.

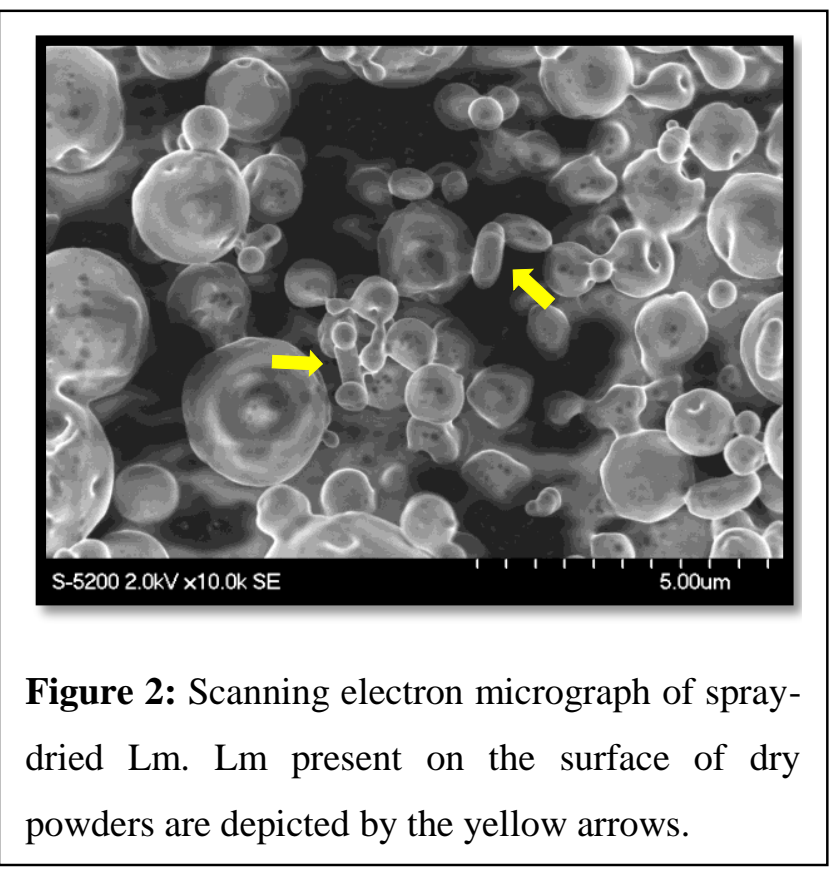

Number of Live Bacteria per Microparticle. The polydispersity of the microparticles obtained after spray-drying makes it difficult for calculating the viable bacterial numbers per microparticle. 
However, we performed a theoretical estimation for the presence of viable microorganisms per particle [46].

Based on the mean dg of our microparticles $(2.24 \pm 0.28 \mu \mathrm{m}$, and corresponding $\mathrm{r}=1.12 \pm 0.14$ $\mu \mathrm{m}$ ), and considering that the microparticles are spherical (Fig. 2), the volume of each microparticle $\left(\mathrm{V}_{1}=4 / 3 \pi \mathrm{r}^{3}\right)$ was $6.40 \times 10^{-12} \mathrm{~mL}$. Moreover, based on the tap density (calculated after mechanically tapping a measuring cylinder containing dry powder until no further change in volume was observed) of our dry powder vaccine $(\rho t=0.38 \mathrm{~g} / \mathrm{mL})$, the volume $\left(\mathrm{V}_{2}\right)$ of $1 \mathrm{~g}$ of our microparticles was approximated to be $2.64 \mathrm{~mL}$. The number of microparticles in $1 \mathrm{~g}$ of powder was calculated to be, $\mathrm{V}_{2} / \mathrm{V}_{1}=4.83 \times 10^{11}$. With a live bacterial loading (cfu counts) of $4.1 \times 10^{7}$ cfu/mg, we demonstrate approximately 1 bacterium per 12 microparticles.

IglC expression in Dry Powders before and after DC2.4 infection. To confirm expression of IglC protein in Lm vaccine powders, Western blot analysis was done. Analysis of the Lm dry powder demonstrated that $\mathrm{IglC}$ protein is present in the powders (Figure 3A). Furthermore, overnight cultures of Lm that are derived from the dry powders can infect DC2.4 cells and produce IglC protein (Figure 3B). 


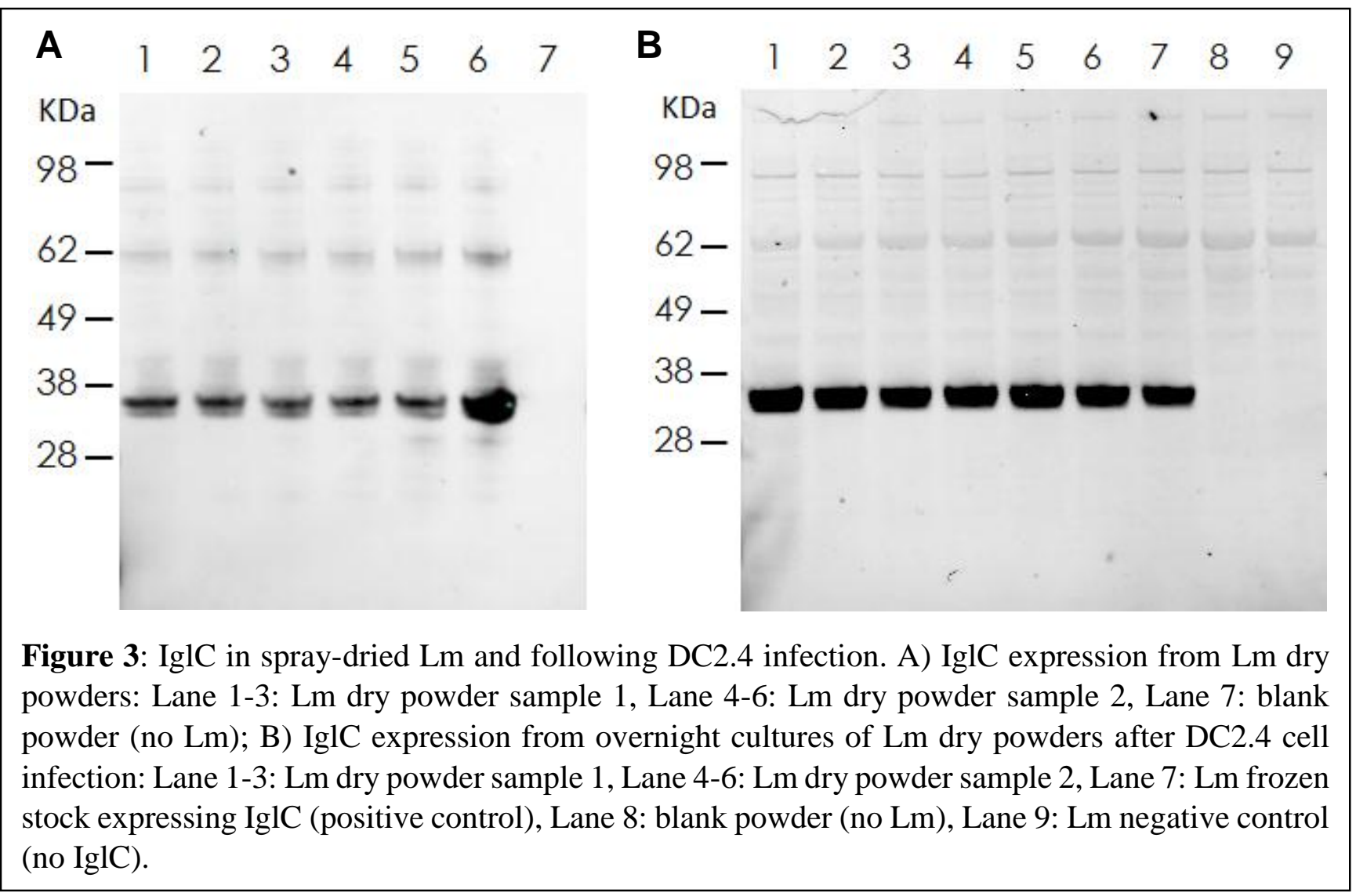

\section{Long-term Storage Stability of the Lm Dry Powders}

The long-term stability of the Lm dry powders were evaluated at different storage conditions as mentioned in Table 2.

Table 2: Different Storage Conditions for Evaluation of the Lm Dry Powder Stability

\begin{tabular}{c|c|ccccc}
\multicolumn{2}{l|}{ Storage Conditions } & $\begin{array}{c}\text { Storage } \\
\text { bottle in the } \\
\text { desiccator }\end{array}$ & $\begin{array}{c}\text { Desiccant } \\
\text { inside bottle }\end{array}$ & $\begin{array}{c}\text { Nitrogen } \\
\text { Gas }\end{array}$ & $\begin{array}{c}\text { Oxygen } \\
\text { Scavenger }\end{array}$ & $\begin{array}{c}\text { Relative } \\
\text { Humidity }\end{array}$ \\
\hline A & No Protection & No & No & No & No & No \\
B & Drierite & Yes & No & No & No & No \\
C & Desiccant Sachet & Yes & Yes & No & No & No \\
D & Inert Gas & Yes & Yes & Yes & No & No \\
E & Free Radical Protection & Yes & Yes & Yes & Yes & No \\
F & ICH Storage Conditions & Yes & Yes & Yes & Yes & Yes
\end{tabular}


No Protection (Condition A). The $\mathrm{Lm}$ powders were initially stored in $20 \mathrm{~mL}$ glass vials at $4{ }^{\circ} \mathrm{C}$, $\mathrm{RT}\left(\sim 23^{\circ} \mathrm{C}\right)$, and $37^{\circ} \mathrm{C}$ in the absence of any of the protective storage conditions mentioned above in Table 2 (Conditions 'B-F'). We observed approximately one log loss in viability after a yearlong storage at $4{ }^{\circ} \mathrm{C}$ (Fig. 4A). Moreover, the Lm powders stored at RT, and $37{ }^{\circ} \mathrm{C}$ showed a rapid loss in viability with no observable colonies at day 50 .

Moisture Protection (Condition B). To provide long-term stability at higher temperature, moisture protection was provided to the Lm powders. The glass vials were placed initially inside a chamber containing Drierite ${ }^{(V W R}$, USA). Interestingly, providing moisture protection improved the Lm viability at RT (Fig. 4B). However, no countable colonies were observed by day 50 at $37{ }^{\circ} \mathrm{C}$.

Condition C. To provide further protection from moisture, a desiccant sachet $\left(0.5 \mathrm{~g}\right.$, Minipax ${ }^{\circledR}$ absorbent packets, Sigma Aldrich) was added to the vial containing Lm powders. Adding a desiccant inside the vial led to an immediate drop in the Lm viability (approx. two log loss in 10 days) at all three temperatures. However, after the initial fall, the bacterial viability stabilized for one year (Fig. 4C). In addition, countable colonies were observed for 150 days at $37{ }^{\circ} \mathrm{C}$; a significant increase in bacterial viability compared to the previous condition where no desiccant was present in the storage vial.

Inert Gas Environment (Condition D). We supplemented the previous condition ' $\mathbf{C}$ ' with an inert gas, nitrogen $\left(\mathrm{N}_{2}\right)$, to the Lm powder storage conditions. For $\mathrm{N}_{2}$ gas purging (Suppl. Fig. 1), we moved from storing the dry powers in glass vials to serum bottles. The addition of an inert gas provided improved stability to the $\mathrm{Lm}$ at $37^{\circ} \mathrm{C}$, with less than two log loss in 60 days (Fig. 4D).

Free Radical Protection (Condition E). We added oxygen scavengers to the previous optimized storage condition. A two-in-one version of desiccant sachet and oxygen scavengers that absorbs 
moisture and oxygen (PharmaKeep ${ }^{\circledR}$ canisters CD-1G or packet KD-20, Mitsubishi Gas Chemical Company, Inc.) were used. We observed minimal loss in bacterial viability for 30 days at $37{ }^{\circ} \mathrm{C}$ (Fig. 4E). Moreover, no colonies were observed at day 15 when no protection was provided similar to initial stability study (condition ' $A$ ').

ICH Storage Conditions (Condition F). After achieving 30 day bacterial viability at $37{ }^{\circ} \mathrm{C}$ based on the optimized condition ' $\mathbf{E}$ ', we assessed Lm viability according to the International Conference on Harmonization (ICH) storage recommendations for vaccines Q1A(R2), and Q5C (40 ${ }^{\circ} \mathrm{C}$ with 15 and $75 \% \mathrm{RH}$ ) [31,32]. The RH was maintained using a saturated salt solution and was monitored using the wireless temp/RH logger. The Lm powders showed minimal loss in viability (approx. half a $\log$ ) at $40{ }^{\circ} \mathrm{C}$ (both 15 and $75 \% \mathrm{RH}$ ) over a 180 day exposure period (Fig. $4 \mathrm{~F}$ ). This data represents excellent viability for spray-dried Lm at high temperature compared to previously published studies with different bacterial strains [14,47,48]. 


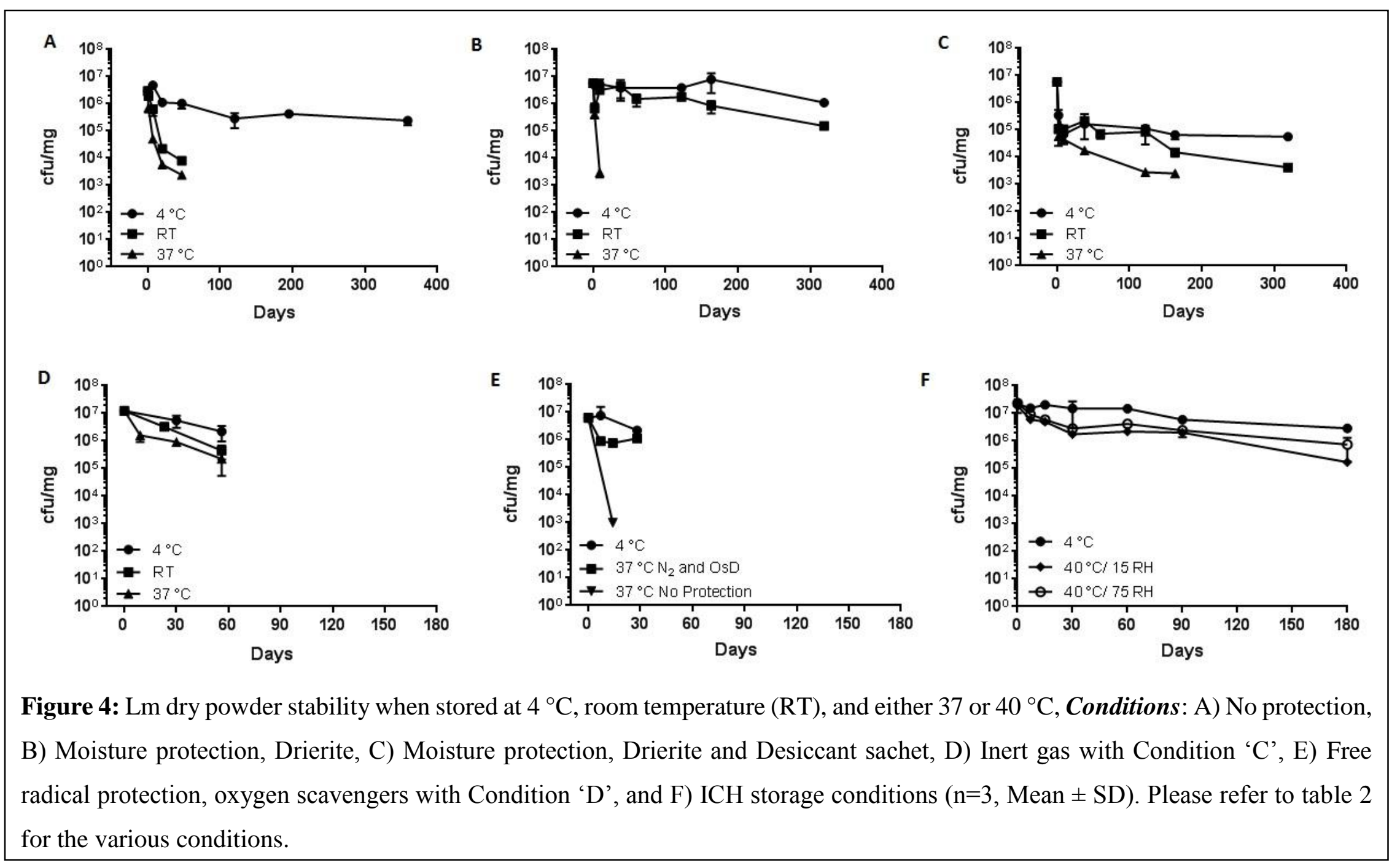


Lm Suspension. As a control, Lm suspension (PBS) was stored unprotected at $4{ }^{\circ} \mathrm{C}$, RT, and 40 ${ }^{\circ} \mathrm{C}$. We observed a $4 \log \operatorname{loss}$ in viability when stored at RT and a $5 \log \operatorname{loss}$ when stored at $40{ }^{\circ} \mathrm{C}$ compared to $4{ }^{\circ} \mathrm{C}$ after 3 weeks (Figure 5). Furthermore, all the samples showed significant loss in viability; a $5 \log \operatorname{loss}$ at $4{ }^{\circ} \mathrm{C}$ and $\mathrm{RT}$, and a $10 \log \operatorname{loss}$ at $40^{\circ} \mathrm{C}$ after 6 weeks.

Liquid Suspension in PBS 4, 25 and 40 C Unprotected

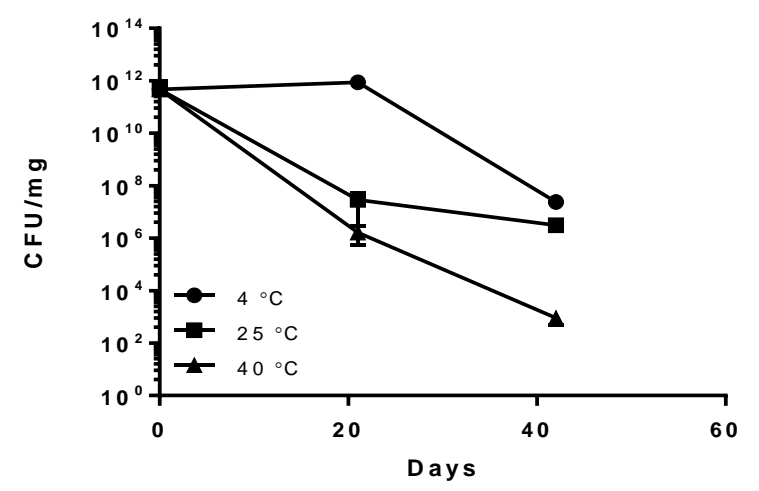

Figure 5: Stability of $\mathrm{Lm}$ in a liquid suspension when stored unprotected at $4{ }^{\circ} \mathrm{C}$, room temperature (RT), and $40{ }^{\circ} \mathrm{C}$ for six weeks ( $\mathrm{n}=3$, Mean \pm SD).

\section{Membrane Integrity Study}

Release of cytoplasmic cell components upon membrane damage was reported by others $[33,49,50]$. The nucleotides (RNA and DNA) released into the medium after cell damage have strong absorbance and can be detected at a UV wavelength of $260 \mathrm{~nm}\left(\mathrm{~A}_{260}\right)$. We observed that Lm dry powders that were unprotected $\left(\mathrm{A}_{260}=0.471\right)$ and exposed to humidity and temperature $\left(37{ }^{\circ} \mathrm{C}, 100 \% \mathrm{RH}\right)$ for 1 week showed similar levels of cell wall damage to that of positive control (sonicated sample, $\left.\mathrm{A}_{260}=0.541\right)$ compared to protected $\left(\mathrm{A}_{260}=0.295\right) \mathrm{Lm}$ dry powder (our modified protected packaging consisting of inert gas, oxygen scavenger, and desiccant sachet). This data is in agreement with our long-term stability data which shows that protected Lm maintain their viability, based on colonies counted, compared to unprotected dry powder Lm. Furthermore, 
this data correlates with our TEM data that show intact membrane integrity pre- and post-spray drying (Fig 1).

\section{Endotoxin Quantification in the Lm Dry Powder}

The endotoxin levels in empty spray-dried powder was $0.033 \mathrm{EU} / \mathrm{mL}$ and Lm spray-dried powders was $0.089 \mathrm{EU} / \mathrm{mL}$ (equivalent to $0.089 \mathrm{EU} / \mathrm{mg}$ ). These values are much below the maximum recommended endotoxin levels for live attenuated vaccine formulations (<200 EU/mL) [51].

\section{Discussion}

Traditional vaccines are formulated as liquids or lyophilized powders requiring uninterrupted cold-chain from manufacture to immunization. The failure of a part of this cold-chain leads to loss in viability. According to the World Health Organization, approximately $50 \%$ of these heatsensitive vaccines are exposed to extreme temperatures rendering them ineffective [52]. In addition, for biodefense vaccines, stockpiling has gained prominence as it allows for quick distribution in case of a biological terror attack [53]. Since such an attack cannot be predicted, it is critical to develop a stable vaccine product with an extended shelf-life. Longer shelf-life will significantly decrease wastage and cost associated with frequent manufacture. In this study, we show short- and long-term viability at different recommended storage conditions of a dry powder vaccine based on live attenuated Lm expressing Ft antigen IglC. We used the spray-drying process to produce Lm dry powders of an approximate particle size of 2-3 $\mu \mathrm{m}$ that can potentially be used for pulmonary immunization [40,54]. For diseases transmitted by aerosols, such as Ft, developing robust immunity in the lung through pulmonary immunization might be important for protective immunity [55]. 
We used non-reducing sugars such as trehalose, inositol, and mannitol to form hydrogen bonds with the phosphate groups of the bacterial membrane to stabilize the bacteria during drying. The protective agents added during drying are known to stabilize the cell membrane by the waterreplacement theory [56-58]. According to this theory, the interactions between the phospholipids and sugar molecules occur via the hydrogen bond between hydroxyl groups of the sugars and the phosphate group in the lipid bilayer/peptidoglycan layer (Fig 6). These hydrogen bonds offer protection during drying [56]. The replacement of water molecules with sugar molecules helps in maintaining the three-dimensional structure of the bacterial cellular membranes by providing sites for hydrogen bonding [57]. However, hydrogen bond formation between Lm and sugars were not performed since such studies require Lm to remain alive and Lm being a BSL-2 agent, it needs to be contained in a biosafety enclosure at all times that makes this study challenging to conduct.

The glassy formation by sugars in a dry state are known to restrict the molecular mobility of these microorganisms preventing aggregation thereby enhancing stability [57,59]. Morgan et al points out that for achieving long-term viability of spray-dried powders, storage conditions such as the temperature, humidity, and presence of oxygen should be delved into more detail [15]. Improper storage often leads to inactivation of the vaccine [60]. Thus, we explored all the above conditions after spray-drying Lm with the goal of providing short- and long-term viability to the live vaccine. Desmond et al has spray-dried Lactobacillus paracasei with a significant drop in viability when stored at 4 and $15{ }^{\circ} \mathrm{C}$ for a month [61]. We recently spray-dried E. coli using lipid-silica matrix and showed dry powders encapsulating the bacteria having an ordered 3D structure and high physical strength [62]. Wong et al has previously spray-dried BCG, a live-attenuated tuberculosis 
vaccine, with leucine and showed minimal loss in viability at 4 and $25^{\circ} \mathrm{C}$ up to 4 months [14]. However, none of these studies show bacterial stability at high temperatures.

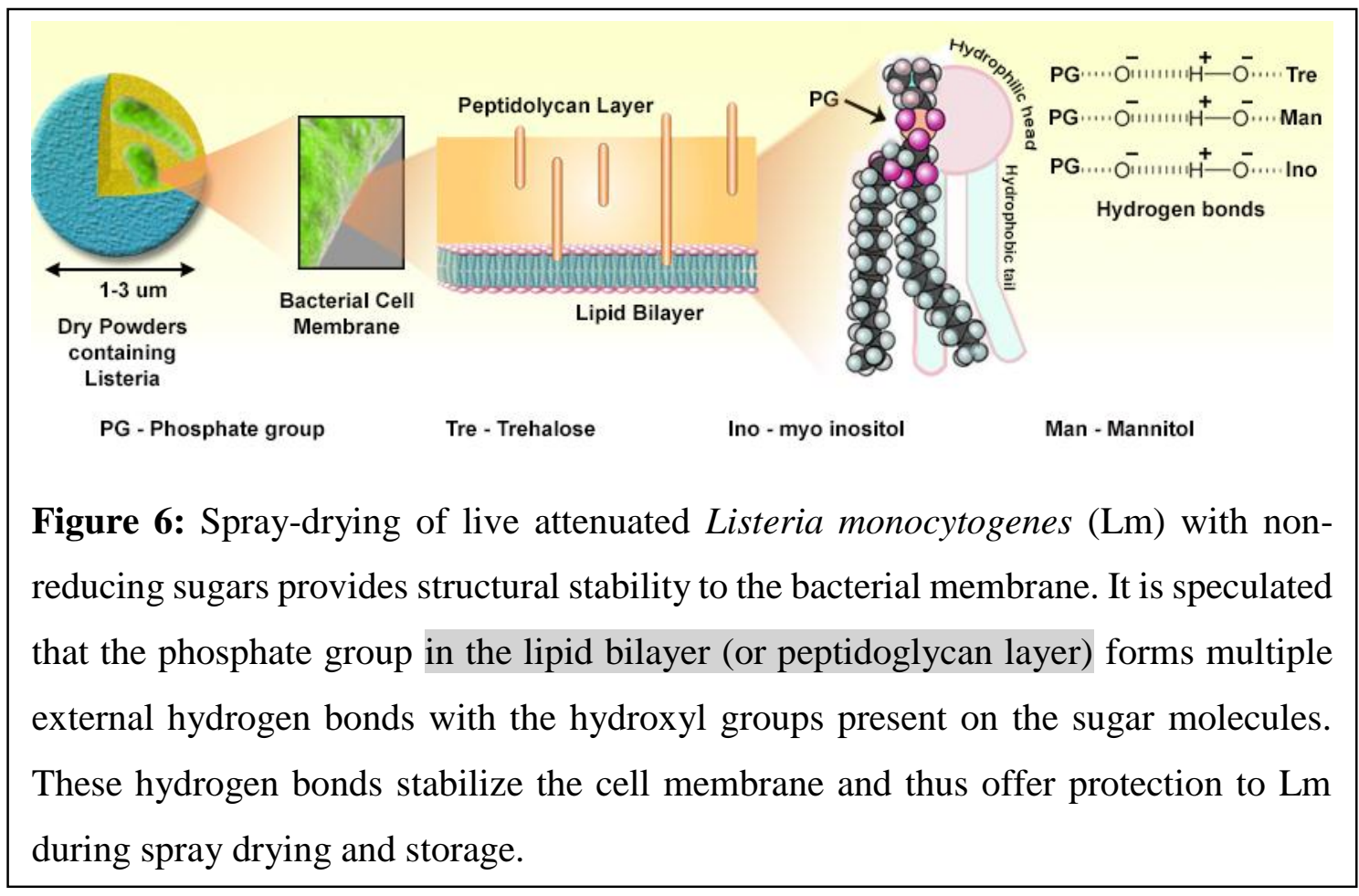

Low moisture content $(\sim 1 \%)$, especially at high temperatures is optimal for long-term stability of live vaccines in a dry powder formulation $[14,44]$. The low moisture in dry powders is also critical to prevent particle agglomeration [40]. Any absorption of water from surrounding environment might change the glassy state of sugars to a rubbery state impacting the viability of the Lm dry powders. In our studies, the Lm dry powders had minimal inherent moisture after spray-drying (< $1 \% \mathrm{w} / \mathrm{w})$. Moreover, a desiccant sachet was added to the storage container to prevent absorption of water from the surrounding environment. The Lm dry powders stored at different conditions after spray-drying have all maintained moisture content <1\% w/w (Supplementary Table 1).

Changes in membrane structure and function could be witnessed due to membrane lipid peroxidation, oxidative DNA or protein damage or a combination of all three during storage at 
extreme conditions. Furthermore, oxidation leads to formation of free radicals increasing the chance of cell death [60]. The reduction of oxygen forms either singlet $\mathrm{O}_{2}$, superoxide radicals $\left(\mathrm{O}_{2}^{-}\right)$, or peroxides $\left(\mathrm{O}_{2}^{2-}\right)$ especially at high temperatures causing destruction of bacterial proteins and cell death possibly due to DNA damage [63-65]. Oxygen free radicals cause fatty acid deesterification from the cell membrane phospholipid. The free fatty acids typically accumulate in desiccated bacterial cells during long-term storage leading to loss in membrane integrity and ultimately cell death [66]. Lm being an aerobic microorganism, any oxygen in the headspace generates free radicals ( $\mathrm{OH}-)$. Given the crucial role oxygen free radicals play in bacterial viability, we displaced the oxygen in the headspace of the container with an inert gas and further added oxygen scavengers to minimize generation of free radicals. We demonstrated improved bacterial stability at room temperature when Lm was incorporated in dry powders compared to an aqueous suspension. This stability is further enhanced by our protective packaging incorporating desiccants, $\mathrm{O}_{2}$ scavenger, and inert atmosphere $\left(\mathrm{N}_{2}\right.$ gas). Further, we have shown that Lm dry powder when unprotected and exposed to humidity and temperature has more cell membrane damage thereby releasing cytoplasmic cell components compared to protected Lm dry powder.

Our modified protective packaging (inert gas $\mathrm{N}_{2}$, oxygen scavengers and desiccant sachet) provided stability to the $\mathrm{Lm}$ vaccine at different storage conditions. We achieved long-term stability with minimal loss in viability at $4{ }^{\circ} \mathrm{C}$ and room temperature for more than a year, and short-term stability at $40{ }^{\circ} \mathrm{C}(15$ and $75 \% \mathrm{RH})$ for 180 days, enough time to administer the vaccines in remote regions without a reliable cold-chain [67]. Our goal for such a vaccine would be to store under refrigeration and transfer to ambient temperature (between $\mathrm{RT}$ and $40^{\circ} \mathrm{C}$ ) during transportation and immunization; the time when maximum breach in storage conditions usually occur. The spray-drying, modified atmosphere packaging, and storage conditions could be 
implemented for other live vaccines currently being tested as a pulmonary immunization strategy $[14,45]$.

Lm can be taken up by phagocytic cells such as DCs and macrophages; uptake by professional antigen-presenting cells is necessary for vaccine potency in the host. We demonstrated that an overnight culture of spray dried Lm can infect DCs and subsequently express IglC protein intracellularly. Antigens expressed intracellularly can be processed and presented via MHC class I and result in efficient priming of antigen-specific T cells. Future studies are required to confirm if this in vitro expression of IglC protein inside DCs can translate into protection against tularemia after immunization in animal models. Further, these dry powder vaccines can be administered to the lungs of preclinical animal models using both passive (nose-only) and active (intratracheal) delivery devices $[54,68,69]$.

Developing thermostable formulations for new and existing vaccines that are resistant to damage by heat could have significant economic and health benefits by reducing vaccine wastage and preventing the adverse consequences of administering ineffective vaccines, respectively. Further, as more vaccines are introduced into the immunization programs causing extra strain on an already over-burdened cold-chain infrastructure, reducing dependence on it will become even more important in the future.

\section{Acknowledgements}

The research was funded by Defense Threat Reduction Agency (HDTRA1-12-C-0046). We would like to thank Erin Benanti, Christopher Rae and Meredith Leong from Aduro Biotech, Inc. for conducting the in vitro Western Blot analysis of IglC presence in the Lm dry powders, the DC infection studies and the subsequent detection of IglC intracellularly and for the constructive 
comments on the manuscript. We also thank Steve Jett for the TEM analysis at the UNM Electron

Microscopy facility.

References

[1] J.B. Ulmer, U. Valley, R. Rappuoli, Vaccine manufacturing: challenges and solutions, Nat Biotechnol. 24 (2006) 1377-1383. doi:10.1038/nbt1261.

[2] P. Lydon, S. Zipursky, C. Tevi-Benissan, M.H. Djingarey, P. Gbedonou, B.O. Youssouf, et al., Economic benefits of keeping vaccines at ambient temperature during mass vaccination: the case of meningitis A vaccine in Chad, Bull. World Health Organ. 92 (2014) 86-92.

[3] L.H. Collier, The development of a stable smallpox vaccine, J. Hyg. (Lond). 53 (1955) 76101.

[4] M.M. Levine, "IDEAL" vaccines for resource poor settings, Vaccine. 29 Suppl 4 (2011) D116-25. doi:10.1016/j.vaccine.2011.11.090.

[5] WHO, Global vaccination targets “off-track” warns WHO, 2015.

[6] T. Sou, E.N. Meeusen, M. de Veer, D.A. V Morton, L.M. Kaminskas, M.P. McIntosh, New developments in dry powder pulmonary vaccine delivery, Trends Biotechnol. 29 (2011) 191-198.

[7] D. Chen, D. Kristensen, Opportunities and challenges of developing thermostable vaccines, Expert Rev. Vaccines. 8 (2009) 547-557. doi:10.1586/erv.09.20.

[8] H.-C. Mahler, R. Müller, W. Friess, A. Delille, S. Matheus, Induction and analysis of aggregates in a liquid IgG1-antibody formulation., Eur. J. Pharm. Biopharm. 59 (2005) 40717. doi:10.1016/j.ejpb.2004.12.004.

[9] E. Tumban, P. Muttil, C.A.A. Escobar, J. Peabody, D. Wafula, D.S. Peabody, et al., Preclinical refinements of a broadly protective VLP-based HPV vaccine targeting the minor capsid protein, L2., Vaccine. 33 (2015) 3346-53. doi:10.1016/j.vaccine.2015.05.016.

[10] N.K. Kunda, S. Somavarapu, S.B. Gordon, G.A. Hutcheon, I.Y. Saleem, Nanocarriers Targeting Dendritic Cells for Pulmonary Vaccine Delivery, Pharm. Res. 30 (2013) 325341. doi:10.1007/s11095-012-0891-5.

[11] P.B. Fourie, W.A. Germishuizen, Y.-L. Wong, D.A. Edwards, Spray drying TB vaccines for pulmonary administration, Expert Opin. Biol. Ther. 8 (2008) 857-863. doi:doi:10.1517/14712598.8.7.857.

[12] G. Pilcer, K. Amighi, Formulation strategy and use of excipients in pulmonary drug delivery, Int. J. Pharm. 392 (2010) 1-19. doi:10.1016/j.ijpharm.2010.03.017. 
[13] M. Potts, Desiccation tolerance of prokaryotes., Microbiol. Rev. 58 (1994) 755-805.

[14] Y.-L. Wong, S. Sampson, W.A. Germishuizen, S. Goonesekera, G. Caponetti, J. Sadoff, et al., Drying a tuberculosis vaccine without freezing, Proc. Natl. Acad. Sci. 104 (2007) 25912595 .

[15] C.A. Morgan, N. Herman, P.A. White, G. Vesey, Preservation of micro-organisms by drying; a review., J. Microbiol. Methods. 66 (2006) 183-93. doi:10.1016/j.mimet.2006.02.017.

[16] R. Vehring, Pharmaceutical Particle Engineering via Spray Drying, Pharm. Res. 25 (2008) 999-1022. doi:10.1007/s11095-007-9475-1.

[17] S. Mitragotri, Immunization without needles, Nat Rev Immunol. 5 (2005) 905-916.

[18] W. Tonnis, A.W. Huckriede, W.J. Hinrichs, H. Frijlink, Pulmonary Administration of Subunit Vaccines, in: C. Foged, T. Rades, Y. Perrie, S. Hook (Eds.), Subunit Vaccine Deliv. SE - 16, Springer New York, 2015: pp. 307-329. doi:10.1007/978-1-4939-1417-3_16.

[19] J. Wayne Conlan, H. Shen, R. Kuolee, X. Zhao, W. Chen, Aerosol-, but not intradermalimmunization with the live vaccine strain of Francisella tularensis protects mice against subsequent aerosol challenge with a highly virulent type A strain of the pathogen by an alphabeta $\mathrm{T}$ cell- and interferon gamma- depende, Vaccine. 23 (2005) 2477-85. doi:10.1016/j.vaccine.2004.10.034.

[20] P.C.F. Oyston, Francisella tularensis: unravelling the secrets of an intracellular pathogen, J. Med. Microbiol. 57 (2008) 921-930. doi:10.1099/jmm.0.2008/000653-0.

[21] L.W. Lamps, J.M. Havens, A. Sjostedt, D.L. Page, M.A. Scott, Histologic and molecular diagnosis of tularemia: a potential bioterrorism agent endemic to North America, Mod Pathol. 17 (2004) 489-495.

[22] P.C.F. Oyston, A. Sjostedt, R.W. Titball, Tularaemia: bioterrorism defence renews interest in Francisella tularensis, Nat Rev Micro. 2 (2004) 967-978.

[23] D. DT, I. TV, H. DA, et al, Tularemia as a biological weapon: Medical and public health management, JAMA. 285 (2001) 2763-2773.

[24] Q. Jia, B.-Y. Lee, D.L. Clemens, R.A. Bowen, M.A. Horwitz, Recombinant attenuated Listeria monocytogenes vaccine expressing Francisella tularensis IglC induces protection in mice against aerosolized Type A F. tularensis., Vaccine. 27 (2009) 1216-29. doi:10.1016/j.vaccine.2008.12.014.

[25] K.L. Elkins, S.C. Cowley, C.M. Bosio, Innate and adaptive immune responses to an intracellular bacterium, Francisella tularensis live vaccine strain, Microbes Infect. 5 (2003) 
135-142. doi:10.1016/S1286-4579(02)00084-9.

[26] D.T. Le, D.G. Brockstedt, R. Nir-Paz, J. Hampl, S. Mathur, J. Nemunaitis, et al., A LiveAttenuated Listeria Vaccine (ANZ-100) and a Live-Attenuated Listeria Vaccine Expressing Mesothelin (CRS-207) for Advanced Cancers: Phase I Studies of Safety and Immune Induction, Clin. Cancer Res. . 18 (2012) 858-868. doi:10.1158/1078-0432.CCR-11-2121.

[27] D.G. Brockstedt, M.A. Giedlin, M.L. Leong, K.S. Bahjat, Y. Gao, W. Luckett, et al., Listeria-based cancer vaccines that segregate immunogenicity from toxicity, Proc. Natl. Acad. Sci. U. S. A. 101 (2004) 13832-13837.

[28] P. Lauer, B. Hanson, E.E. Lemmens, W. Liu, W.S. Luckett, M.L. Leong, et al., Constitutive Activation of the PrfA Regulon Enhances the Potency of Vaccines Based on LiveAttenuated and Killed but Metabolically Active Listeria monocytogenes Strains , Infect. Immun. 76 (2008) 3742-3753. doi:10.1128/IAI.00390-08.

[29] K.W. Bruhn, N. Craft, J.F. Miller, Listeria as a vaccine vector., Microbes Infect. 9 (2007) 1226-35. doi:10.1016/j.micinf.2007.05.010.

[30] E.G. Pamer, Immune responses to Listeria monocytogenes, Nat Rev Immunol. 4 (2004) 812-823.

[31] ICH Expert Working Group, ICH Quality Guidelines Q1A(R2): Stability Testing of New Drug Substances and Products, (2003) 1-24. http://www.ich.org/products/guidelines/quality/article/quality-guidelines.html.

[32] ICH Expert Working Group, ICH Guidelines Q5C: Stability Testing of Biotechnological/Biological Products, (1995) 1-10. http://www.ich.org/products/guidelines/quality/article/quality-guidelines.html.

[33] C.Z. Chen, S.L. Cooper, Interactions between dendrimer biocides and bacterial membranes, Biomaterials. 23 (2002) 3359-3368. doi:http://dx.doi.org/10.1016/S0142-9612(02)000364.

[34] E.M. Littringer, R. Paus, A. Mescher, H. Schroettner, P. Walzel, N.A. Urbanetz, The morphology of spray dried mannitol particles-The vital importance of droplet size, Powder Technol. 239 (2013) 162-174.

[35] T.H. Jin, E. Tsao, J. Goudsmit, V. Dheenadhayalan, J. Sadoff, Stabilizing formulations for inhalable powders of an adenovirus 35-vectored tuberculosis (TB) vaccine (AERAS-402), Vaccine. 28 (2010) 4369-4375. doi:10.1016/j.vaccine.2010.04.059.

[36] Y. Zeng, H. Fan, G. Chiueh, B. Pham, R. Martin, D. Lechuga-Ballesteros, et al., Towards development of stable formulations of a live attenuated bacterial vaccine: a preformulation study facilitated by a biophysical approach, Hum. Vaccin. 5 (2009) 322-331. 
[37] S. Ohtake, R.A. Martin, A. Saxena, D. Lechuga-ballesteros, A.E. Santiago, E.M. Barry, et al., Formulation and stabilization of Francisella tularensis live vaccine strain, J. Pharm. Sci. 100 (2011) 3076-3087.

[38] W.F. Tonnis, J.-P. Amorij, M.A. Vreeman, H.W. Frijlink, G.F. Kersten, W.L.J. Hinrichs, Improved storage stability and immunogenicity of hepatitis B vaccine after spray-freeze drying in presence of sugars, Eur. J. Pharm. Sci. 55 (2014) 36-45.

[39] A. Millqvist-Fureby, M. Malmsten, B. Bergenståhl, An aqueous polymer two-phase system as carrier in the spray-drying of biological material, J. Colloid Interface Sci. 225 (2000) 5461.

[40] N.K. Kunda, I.M. Alfagih, S.R. Dennison, S. Somavarapu, Z. Merchant, G. a. Hutcheon, et al., Dry powder pulmonary delivery of cationic PGA-co-PDL nanoparticles with surface adsorbed model protein, Int. J. Pharm. 492 (2015) 213-222. doi:10.1016/j.ijpharm.2015.07.015.

[41] N.K. Kunda, I.M. Alfagih, S.R. Dennison, H.M. Tawfeek, S. Somavarapu, G.A. Hutcheon, et al., Bovine Serum Albumin Adsorbed PGA-co-PDL Nanocarriers for Vaccine Delivery via Dry Powder Inhalation, Pharm. Res. (2014) 1-13. doi:10.1007/s11095-014-1538-5.

[42] L. Garcia-Contreras, Y.-L. Wong, P. Muttil, D. Padilla, J. Sadoff, J. DeRousse, et al., Immunization by a bacterial aerosol, Proc. Natl. Acad. Sci. 105 (2008) 4656-4660. doi:10.1073/pnas.0800043105.

[43] W.-H. Lin, D.E. Griffin, P.A. Rota, M. Papania, S.P. Cape, D. Bennett, et al., Successful respiratory immunization with dry powder live-attenuated measles virus vaccine in rhesus macaques, Proc. Natl. Acad. Sci. 108 (2011) 2987-2992. doi:10.1073/pnas.1017334108.

[44] J.L. Burger, S.P. Cape, C.S. Braun, D.H. McAdams, J.A. Best, P. Bhagwat, et al., Stabilizing formulations for inhalable powders of live-attenuated measles virus vaccine, J. Aerosol Med. Pulm. Drug Deliv. 21 (2008) 25-34.

[45] S. Agarkhedkar, P.S. Kulkarni, S. Winston, R. Sievers, R.M. Dhere, B. Gunale, et al., Safety and immunogenicity of dry powder measles vaccine administered by inhalation: a randomized controlled Phase I clinical trial, Vaccine. 32 (2014) 6791-6797.

[46] C. Amiet-Charpentier, P. Gadille, B. Digat, J.P. Benoit, Microencapsulation of rhizobacteria by spray-drying: Formulation and survival studies, J. Microencapsul. 15 (1998) 639-659. doi:10.3109/02652049809008247.

[47] B.M. Corcoran, R.P. Ross, G.F. Fitzgerald, C. Stanton, Comparative survival of probiotic lactobacilli spray-dried in the presence of prebiotic substances, J. Appl. Microbiol. 96 (2004) 1024-1039. doi:10.1111/j.1365-2672.2004.02219.x.

[48] G.E. Gardiner, E. O’Sullivan, J. Kelly, M.A.E. Auty, G.F. Fitzgerald, J.K. Collins, et al., 
Comparative Survival Rates of Human-Derived Probiotic Lactobacillus paracasei and L. salivarius Strains during Heat Treatment and Spray Drying, Appl. Environ. Microbiol. 66 (2000) 2605-2612.

[49] W.H. Greene, Biochemistry of Antimicrobial Action. 2(nd) Edition, Yale J. Biol. Med. 50 (1977) 87-88.

[50] J.-Y. Maillard, Bacterial target sites for biocide action, J. Appl. Microbiol. 92 (2002) 16S27S. doi:10.1046/j.1365-2672.92.5s1.3.x.

[51] L.A. Brito, M. Singh, Acceptable levels of endotoxin in vaccine formulations during preclinical research, J. Pharm. Sci. 100 (2011) 34-37. doi:10.1002/jps.22267.

[52] WHO, Monitoring vaccine wastage at country level Guidelines for programme managers, 2003.

[53] A.D.T. Barrett, D.W.C. Beasley, Development pathway for biodefense vaccines, Vaccine. 27 (2009) D2-D7.

[54] P. Muttil, B. Pulliam, L. Garcia-Contreras, J. Fallon, C. Wang, A. Hickey, et al., Pulmonary Immunization of Guinea Pigs with Diphtheria CRM-197 Antigen as Nanoparticle Aggregate Dry Powders Enhance Local and Systemic Immune Responses, AAPS J. 12 (2010) 699-707. doi:10.1208/s12248-010-9229-6.

[55] M.K. McLendon, M.A. Apicella, L.-A.H. Allen, Francisella tularensis: taxonomy, genetics, and immunopathogenesis of a potential agent of biowarfare, Annu. Rev. Microbiol. 60 (2006) 167.

[56] C. Santivarangkna, U. Kulozik, P. Foerst, Inactivation mechanisms of lactic acid starter cultures preserved by drying processes, J. Appl. Microbiol. 105 (2008) 1-13.

[57] S.H. Peighambardoust, A. Golshan Tafti, J. Hesari, Application of spray drying for preservation of lactic acid starter cultures: a review, Trends Food Sci. Technol. 22 (2011) 215-224. doi:10.1016/j.tifs.2011.01.009.

[58] J.H. Crowe, L.M. Crowe, J.F. Carpenter, Preserving dry biomaterials: the water replacement hypothesis, part 1, BIOPHARM-EUGENE-. 6 (1993) 28.

[59] J.H. Crowe, J.F. Carpenter, L.M. Crowe, The role of vitrification in anhydrobiosis, Annu. Rev. Physiol. 60 (1998) 73-103.

[60] M. Aschenbrenner, U. Kulozik, P. Foerst, Evaluation of the relevance of the glassy state as stability criterion for freeze-dried bacteria by application of the Arrhenius and WLF model., Cryobiology. 65 (2012) 308-18. doi:10.1016/j.cryobiol.2012.08.005.

[61] C. Desmond, R.P. Ross, E. O’Callaghan, G. Fitzgerald, C. Stanton, Improved survival of 
Lactobacillus paracasei NFBC 338 in spray-dried powders containing gum acacia, J. Appl. Microbiol. 93 (2002) 1003-1011. doi:10.1046/j.1365-2672.2002.01782.x.

[62] P.E. Johnson, P. Muttil, D. MacKenzie, E.C. Carnes, J. Pelowitz, N.A. Mara, et al., SprayDried Multiscale Nano-biocomposites Containing Living Cells, ACS Nano. 9 (2015) 69616977. doi:10.1021/acsnano.5b01139.

[63] S. Akasaka, Inactivation of transforming activity of plasmid DNA by lipid peroxidation, Biochim. Biophys. Acta (BBA)-Gene Struct. Expr. 867 (1986) 201-208.

[64] H. Castro, P. Teixeira, R. Kirby, Changes in the cell membrane of Lactobacillus bulgaricus during storage following freeze-drying, Biotechnol. Lett. 18 (1996) 99-104. doi:10.1007/BF00137819.

[65] A.M. Hruszkewycz, Evidence for mitochondrial DNA damage by lipid peroxidation, Biochem. Biophys. Res. Commun. 153 (1988) 191-197.

[66] M.B. França, A.D. Panek, E.C.A. Eleutherio, Oxidative stress and its effects during dehydration, Comp. Biochem. Physiol. Part A Mol. Integr. Physiol. 146 (2007) 621-631. doi:http://dx.doi.org/10.1016/j.cbpa.2006.02.030.

[67] S. Zipursky, M.H. Djingarey, J.-C. Lodjo, L. Olodo, S. Tiendrebeogo, O. Ronveaux, Benefits of using vaccines out of the cold chain: delivering meningitis A vaccine in a controlled temperature chain during the mass immunization campaign in Benin., Vaccine. 32 (2014) 1431-5. doi:10.1016/j.vaccine.2014.01.038.

[68] P. Muttil, J. Kaur, K. Kumar, A.B. Yadav, R. Sharma, A. Misra, Inhalable microparticles containing large payload of anti-tuberculosis drugs, Eur. J. Pharm. Sci. 32 (2007) 140-150. doi:http://dx.doi.org/10.1016/j.ejps.2007.06.006.

[69] J. Kaur, P. Muttil, R.K. Verma, K. Kumar, A.B. Yadav, R. Sharma, et al., A hand-held apparatus for "nose-only" exposure of mice to inhalable microparticles as a dry powder inhalation targeting lung and airway macrophages, Eur. J. Pharm. Sci. 34 (2008) 56-65. doi:http://dx.doi.org/10.1016/j.ejps.2008.02.008. 

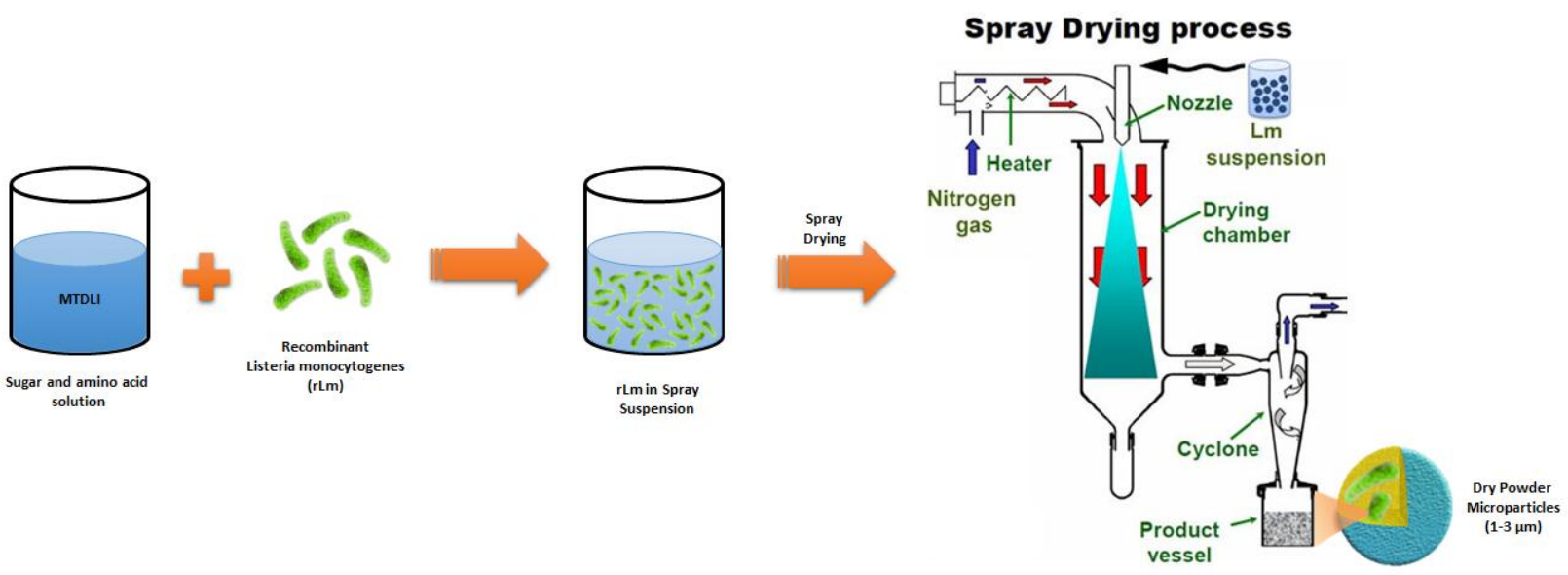